NASA/TM-2008-215432

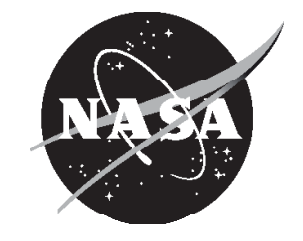

\title{
Comparison Between Numerically Simulated and Experimentally Measured Flowfield Quantities Behind a Pulsejet
}

Tao Geng

North Carolina State University, Raleigh, North Carolina

Daniel E. Paxson

Glenn Research Center, Cleveland, Ohio

Fei Zheng, Andrey V. Kuznetsov, and William L. Roberts

North Carolina State University, Raleigh, North Carolina 


\section{NASA STI Program . . . in Profile}

Since its founding, NASA has been dedicated to the advancement of aeronautics and space science. The NASA Scientific and Technical Information (STI) program plays a key part in helping NASA maintain this important role.

The NASA STI Program operates under the auspices of the Agency Chief Information Officer. It collects, organizes, provides for archiving, and disseminates NASA's STI. The NASA STI program provides access to the NASA Aeronautics and Space Database and its public interface, the NASA Technical Reports Server, thus providing one of the largest collections of aeronautical and space science STI in the world. Results are published in both non-NASA channels and by NASA in the NASA STI Report Series, which includes the following report types:

- TECHNICAL PUBLICATION. Reports of completed research or a major significant phase of research that present the results of NASA programs and include extensive data or theoretical analysis. Includes compilations of significant scientific and technical data and information deemed to be of continuing reference value. NASA counterpart of peer-reviewed formal professional papers but has less stringent limitations on manuscript length and extent of graphic presentations.

- TECHNICAL MEMORANDUM. Scientific and technical findings that are preliminary or of specialized interest, e.g., quick release reports, working papers, and bibliographies that contain minimal annotation. Does not contain extensive analysis.

- CONTRACTOR REPORT. Scientific and technical findings by NASA-sponsored contractors and grantees.

- CONFERENCE PUBLICATION. Collected papers from scientific and technical conferences, symposia, seminars, or other meetings sponsored or cosponsored by NASA.

- SPECIAL PUBLICATION. Scientific, technical, or historical information from NASA programs, projects, and missions, often concerned with subjects having substantial public interest.

- TECHNICAL TRANSLATION. Englishlanguage translations of foreign scientific and technical material pertinent to NASA's mission.

Specialized services also include creating custom thesauri, building customized databases, organizing and publishing research results.

For more information about the NASA STI program, see the following:

- Access the NASA STI program home page at http://www.sti.nasa.gov

- E-mail your question via the Internet to help@ sti.nasa.gov

- Fax your question to the NASA STI Help Desk at 301-621-0134

- Telephone the NASA STI Help Desk at 301-621-0390

- Write to: NASA Center for AeroSpace Information (CASI) 7115 Standard Drive Hanover, MD 21076-1320 
NASA/TM-2008-215432

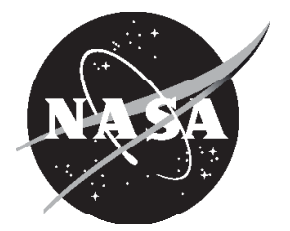

\section{Comparison Between Numerically Simulated and Experimentally Measured Flowfield Quantities Behind a Pulsejet}

Tao Geng

North Carolina State University, Raleigh, North Carolina

Daniel E. Paxson

Glenn Research Center, Cleveland, Ohio

Fei Zheng, Andrey V. Kuznetsov, and William L. Roberts

North Carolina State University, Raleigh, North Carolina

Prepared for the

44th Joint Propulsion Conference and Exhibit

cosponsored by AIAA, ASME, SAE, and ASEE

Hartford, Connecticut, July 21-23, 2008

National Aeronautics and

Space Administration

Glenn Research Center

Cleveland, Ohio 44135 
This report is a formal draft or working paper, intended to solicit comments and ideas from a technical peer group.

This report contains preliminary findings, subject to revision as analysis proceeds.

Trade names and trademarks are used in this report for identification only. Their usage does not constitute an official endorsement, either expressed or implied, by the National Aeronautics and Space Administration.

This work was sponsored by the Fundamental Aeronautics Program at the NASA Glenn Research Center.

Level of Review: This material has been technically reviewed by technical management.

Available from

NASA Center for Aerospace Information 7115 Standard Drive

Hanover, MD 21076-1320
National Technical Information Service 5285 Port Royal Road Springfield, VA 22161 


\title{
Comparison Between Numerically Simulated and Experimentally Measured Flowfield Quantities Behind a Pulsejet
}

\author{
Tao Geng \\ North Carolina State University \\ Raleigh, North Carolina 27695 \\ Daniel E. Paxson \\ National Aeronautics and Space Administration \\ Glenn Research Center \\ Cleveland, Ohio 44135 \\ Fei Zheng, Andrey V. Kuznetsov, and William L. Roberts \\ North Carolina State University \\ Raleigh, North Carolina 27695
}

\begin{abstract}
Pulsed combustion is receiving renewed interest as a potential route to higher performance in air breathing propulsion systems. Pulsejets offer a simple experimental device with which to study unsteady combustion phenomena and validate simulations. Previous computational fluid dynamic (CFD) simulation work focused primarily on the pulsejet combustion and exhaust processes. This paper describes a new inlet sub-model which simulates the fluidic and mechanical operation of a valved pulsejet head. The governing equations for this sub-model are described. Sub-model validation is provided through comparisons of simulated and experimentally measured reed valve motion, and time averaged inlet mass flow rate. The updated pulsejet simulation, with the inlet sub-model implemented, is validated through comparison with experimentally measured combustion chamber pressure, inlet mass flow rate, operational frequency, and thrust. Additionally, the simulated pulsejet exhaust flowfield, which is dominated by a starting vortex ring, is compared with particle imaging velocimetry (PIV) measurements on the bases of velocity, vorticity, and vortex location. The results show good agreement between simulated and experimental data. The inlet sub-model is shown to be critical for the successful modeling of pulsejet operation. This sub-model correctly predicts both the inlet mass flow rate and its phase relationship with the combustion chamber pressure. As a result, the predicted pulsejet thrust agrees very well with experimental data.
\end{abstract}

\section{Nomenclature}

$A_{e} \quad$ Exit plane area

$A_{\text {in }} \quad$ Inlet cross sectional area

$A_{v} \quad$ Reed valve flow area

$A_{v_{\text {min }}} \quad$ Minimal reed valve flow area

$\mathrm{g}_{\mathrm{c}} \quad$ Newton constant

$k_{v} \quad$ Reed valve spring constant

$L_{\text {in }} \quad$ Length of the upstream end of the inlet

$m_{v} \quad$ Reed valve mass

$\dot{m} \quad$ Inlet mass flow rate

$\dot{m}_{e} \quad$ Exit plane mass flow rate

$P_{c c} \quad$ Combustion chamber pressure

$P_{i n} \quad$ Pressure at the upstream end of the inlet

$P_{0} \quad$ Ambient total pressure

$P_{u p} \quad$ Pressure just upstream of the reed valve 


$\begin{array}{ll}V_{e} & \text { Exit plane average velocity } \\ V_{i n} & \text { Inlet velocity } \\ V_{v} & \text { Reed valve velocity } \\ x_{v} & \text { Reed valve position } \\ \alpha & \text { Proportionality constant relating open reed valve area to its position } \\ \rho & \text { density } \\ \tau & \text { Thrust }\end{array}$

\section{Introduction}

The pulsejet is of interest both due to the complexity of the fundamentally unsteady, reactive flowfield and due to its potential applications to create low-cost, scalable, high thrust-to-weight ratio propulsion devices (refs. 1 and 2). There is also renewed interest in the application of pulsed combustion devices for achieving pressure-gain heat addition in gas turbine systems (ref. 3).

Detailed descriptions of the mechanically-valved pulsejet operational cycle can be found in the literature (refs. 4 and 5); however, it may briefly be described as follows. Referring to figure 1, the cycle may be divided into three phases

(1) Combustion-Reaction of an air and fuel mixture within the combustion chamber commences. The pressure begins to rise as a result of confinement of the flow. The pressure rise causes the inlet valves to close, preventing backflow. The reaction accelerates as the pressure and temperature rise; this, in turn, accelerates the pressure and temperature rise.

(2) Expansion-The hot, high-pressure gases in the combustion chamber expand, forcing flow through the exhaust.

(3) Ingestion-The momentum of the exhaust gases causes the combustion-chamber pressure to drop below the ambient value. This allows the inlet valves to open and a fresh charge of air to enter (mixed with fuel). Eventually, the exiting exhaust flow reverses and mixes with the fresh charge. This initiates a new reaction, and the cycle begins again.

The design and optimization of any pulsed combustion system will rely on accurate flowfield simulations. However, the flowfield, both internal and external, is very complex. For example, the exhaust flow contains a strong starting vortex common to all unsteady, thrust producing flows. The starting vortex has been extensively studied both experimentally and computationally (refs. 6 to 13), in a variety of unsteady devices. However, in most of that work, the flowfields are not nearly as complex as that of the pulsejet. That is to say, they do not contain comparable turbulence levels, driver and driven enthalpy ratios, vorticity levels, or accelerations. Other challenges include predicting the periodic combustion process, the associated pressure rise in the combustion chamber, and the complex, coupled gasdynamic processes in the tailpiece that result in resonant operation. The inlet mass flow, which is a function of the spring force of the reed valve, the combustion chamber pressure and the upstream flow properties, needs to be modeled precisely to provide appropriate response to the internal flowfield variations between cycles. In other words, simulations should be able to model the self-aspirating phenomena of pulsejets. There have been limited numerical studies of pulsejet flows (e.g., refs. 14 to 17), and some experimental flowfield measurements (beyond just thrust) (ref. 18). However, the two have rarely been directly compared, and without such comparisons, or validation efforts, conclusions drawn from the computational work are less certain. This paper represents a first step toward that end.

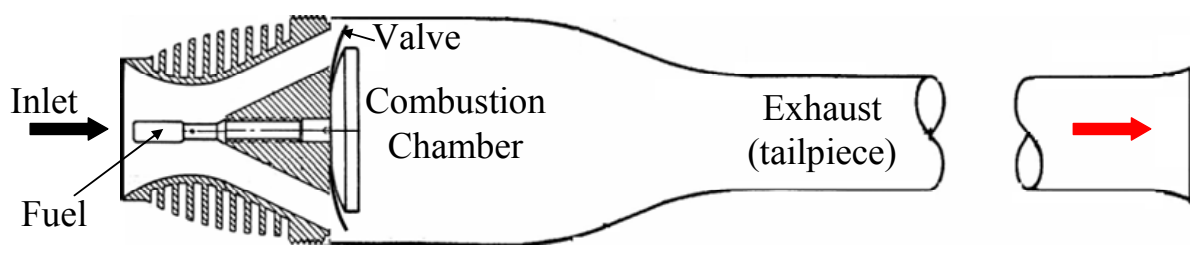

Figure 1.-Pulsejet schematic 
Using an experimentally guided, computational fluid dynamic approach, previous work (refs. 17 to 19) established simulation models and studied the operation of various pulsejet configurations. Numerical simulations were performed utilizing CFX, a commercially available, 3-D, compressible, viscous, computational fluid dynamics (CFD) code. In order to capture wave motions and their interactions and to minimize numerical diffusion in the simulations, second order advection schemes were always used to calculate the advection terms in the discrete finite volume equations. The CFD mesh and time step were optimized to ensure mesh-independent results. These simulations provided physical insights into the pulsejets operation. Pressure, mean temperature, exit velocity, static thrust, and operational frequency were compared between simulation results and limited experimental data. Although the results showed good agreement in pressure, temperature, exhaust plane velocity, and frequency, simulated total thrust and inlet mass flow rate were less than those obtained in experiments. This was due to the fact that the pulsejet valve head, which essentially consisted of a short duct and a reed valve, was not fully modeled. Instead the flow through the valve was modeled using an inlet boundary condition (ref. 17) that defined the inlet velocity (at standard temperature and pressure) as a linear function of the pressure difference between the ambient pressure and the combustion chamber pressure. This function, based on experimental measurements, is given below:

$$
V_{i n}=\begin{gathered}
3\left(P_{0}-P_{c c}\right) / 1000 ; P_{c c} \leq P_{0} \\
0 ; P_{c c}>P_{0}
\end{gathered}
$$

where $P_{c c}$ is the pressure immediately after the reed valves and $P_{0}$ is the ambient pressure. Clearly this simple function could not model the inertia effect of the upstream flow in the valve head and valve motions, resulting in a poor prediction of the inlet mass flow rate and its phase relation to the time varying combustion chamber pressure.

The objective of this paper is to improve the simulation model through a modified sub-model of the inlet and reed valves. Similar to the previous work, pressure and velocity data will be compared to experimental data. However, this paper will concentrate on the flowfield behind or downstream of the pulsejet exit plane. This is the region where the starting vortex is formed, and arguably represents the most intriguing and challenging region of the flow. Furthermore, the emitted vortex has been strongly tied to the very high levels of entrainment, mixing, and thrust augmentation observed when pulsejets are used in conjunction with ejectors (refs. 20 and 21). Maximizing this augmentation represents enabling technology for many potential pulsejet-based applications. It is therefore critical to validate the developed simulation code in this flow region.

Furthermore, a detailed set of experimentally measured, velocity related quantities have been obtained in this region and can serve as a set of valuable validation data; particularly since the simulated pulsejet was identical to the one used for the velocity measurements. The experimental data, obtained using particle imaging velocimetry (PIV), were collected in the same manner described in reference 13 (and will therefore not be presented here). In fact, the same equipment and laboratory setting were used. However, for the reference 13 measurements, an ejector was present in the exhaust region. For the present work, the ejector was removed.

\section{Simulation Model}

\section{Simulation Model and Grid}

Unless specifically stated in this paper the simulation model shares similar features as those in previous work (refs. 17 to 19). Figure 2 shows the dimensions of the computational domain used in simulating the pulsejet and external flowfield. These dimensions match those of the experimental device

to which comparison will be made. The model assumes that the flow is 2-D axis-symmetric and only 1/90 


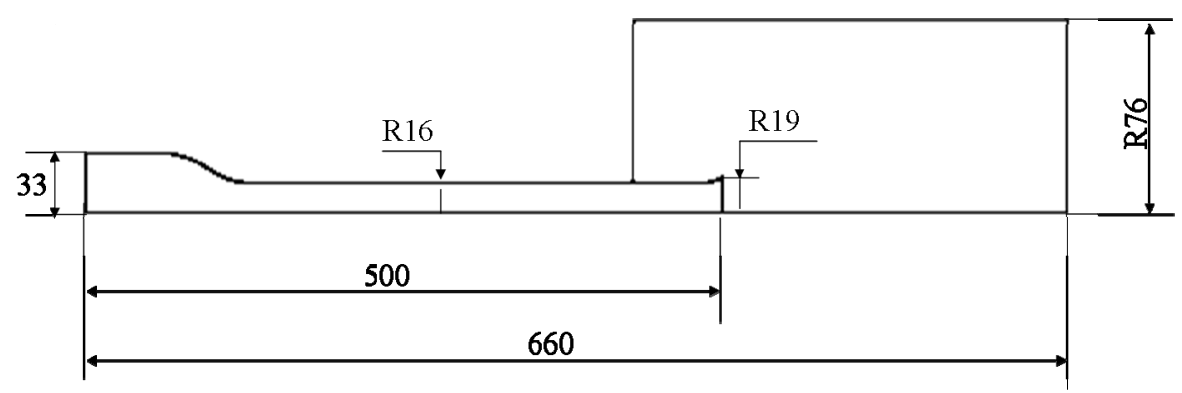

Figure 2.-Dimensions of the simulated pulsejet flowfield ( $\mathrm{mm})$.

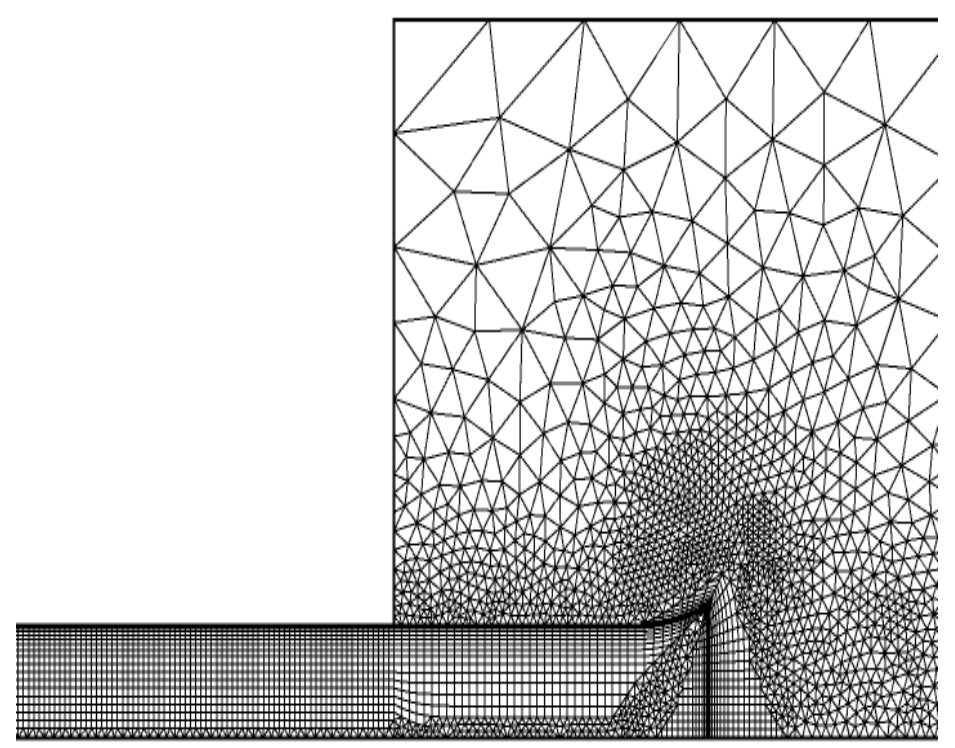

Figure 3.-Hybrid mesh for the pulsejet simulation.

in the $\theta$-direction of the whole domain is modeled. The turbulent flow and premixed propane combustion are modeled with the Shear-Stress-Transport (SST) model and Eddy Dissipation Model, respectively ${ }^{1}$. The $k$ - $\omega$ based SST model is used to give highly accurate predictions of the onset and the amount of flow separation under adverse pressure gradients by the inclusion of transport effects into the eddy-viscosity formulation. The result is a major improvement in terms of predicting flow separation, which is expected to occur in the flared region of the pulsejet tailpiece. The effectiveness of this approach has been demonstrated in a large number of validation studies (ref. 22). The viscous effect in the boundary layer region is modeled by the CFX automatic near-wall treatment which automatically switches from wallfunctions to a low-Reynolds near wall formulation as the mesh is refined. However, to take advantage of the reduction in errors offered by this low-Reynolds formulation, at least 10 nodes must be put in the boundary layer, causing a considerable increase of mesh size. A hybrid high quality mesh is created to ensure fine hex-mesh in the near wall region and exit plane while relatively coarse tet-mesh in part of the external flowfield, as shown in figure 3.

\footnotetext{
${ }^{1}$ The experimental pulsejet to which comparison will be made was actually liquid-fueled, with gasoline. However, accurately modeling the complexities of liquid droplet sprays, vaporization, etc. was considered beyond the scope of this work.
} 
There are total 13766 elements, of which 362 are tet-meshes. The computations are performed on the North Carolina State IBM Blade center utilizing a single 3.0 GHz Intel Xeon processor. With a $1.0 \mu$ sec. time step, the computation time for one cycle is about $24 \mathrm{hr}$.

\section{Inlet Sub-model}

The computational simulation includes a modified sub-model of the inlet and reed valve section that is more realistic than previously used (ref. 17). This sub-model is implemented as a boundary condition controlling the mass flow rate of the premixed reactants into the combustion chamber. As shown in figure 4, the mass flow rate is a function of pressure in the valve head and combustion chamber pressure. The valve motion is a function of spring force and pressure forces acting on both sides of the valve. These two processes are coupled in the sub-model. The inlet flow and reed valve dynamics are modeled by solving three ordinary differential equations that describe their motions.

$$
\begin{gathered}
\frac{d \dot{m}}{d t}=12 \frac{A_{\text {in }}}{L_{\text {in }}} g_{c}\left(P_{\text {in }}-P_{u p}\right) \\
\frac{d V_{v}}{d t}=\frac{12 g_{c}}{m_{v}}\left[A_{\text {in }}\left(P_{u p}-P_{c c}\right)-k_{v} x_{v}\right] \\
\frac{d x_{v}}{d t}=V_{v}
\end{gathered}
$$

The quantities $P_{u p}$, and $A_{v}$ are found from the following relations.

$$
P_{u p}=\begin{gathered}
P_{c c}+\frac{\dot{m}^{2}}{12 g_{c} 2 \rho}\left(\frac{1}{A_{v}{ }^{2}}-\frac{1}{A_{i n}{ }^{2}}\right), \dot{m} \geq 0.0 \\
P_{c c}-\frac{\dot{m}^{2}}{12 g_{c} 2 \rho A_{v}{ }^{2}}, \dot{m}<0.0 \\
A_{v}=\max \left(A_{v_{-} \text {min }}, \alpha x_{v}\right)
\end{gathered}
$$

Equation (2) describes the mass flow rate and equations (3) and (4) describe the valve motion. The combustion chamber pressure, $P_{c c}$, is the force function calculated by the code. At each timestep, the submodel calculates the new mass flow rate based on the current combustion chamber pressure and returns this value to the code, where inlet mass flow rate is specified. Equations (2) through (4) are integrated using a simple, first-order Euler method, with a time step equal to that of the pulsejet simulation.

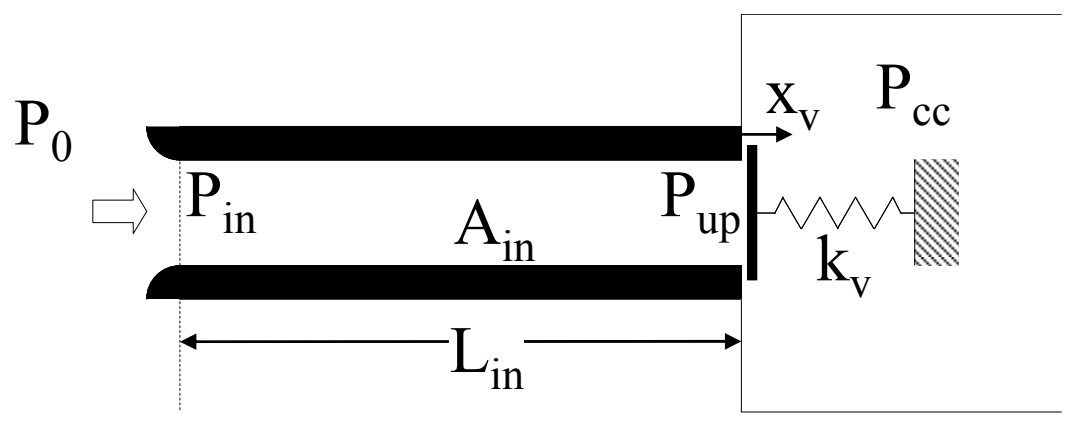

Figure 4.-Valve head model schematic. 
Figure 5 shows the sub-model response to a sinusoidal variation of the downstream combustion chamber pressure (representing resonant pulsejet operation). The simulation results show that the maximum mass flow rate across the valve does not occur at the lowest combustion chamber pressure, as might be expected and implied in the previous work. Furthermore, flow into the inlet does not stop when the combustion chamber pressure exceeds the ambient pressure (101325 Pa). This sub-model has been partially validated by comparing simulated and experimentally measured reed valve positions and combustion chamber pressures during limit cycle operation, as explained next.

Figure 6 shows the experimental data of combustion chamber pressure and valve position over the course of one cycle. This trace should be compared to figure 5(b). The pressure transducer installation is described in reference 20 . The valve position is measured using specially fabricated fiber-optic sensor which is described in the Appendix. The sensor is not calibrated, since the design is crude, and accuracy is not expected. The intention of the measurement is to obtain information on when the valve opens and closes relative to the combustion chamber pressure. The precise position is not particularly important. As such, the position data is shown simply as sensor voltage subtracted from the voltage reading when the valve is in the closed position (sensor voltage drops when the valve opens). The experimental data of figure 6 looks quite similar to that of figure 5(b). In particular, the valve is still open after the combustion chamber pressure exceeds the ambient pressure, and it remains closed even after the combustion chamber pressure drops below ambient. Thus, the valve head sub-model and experimental similarities, while not conclusive, do suggest that the sub-model approach used here is valid.

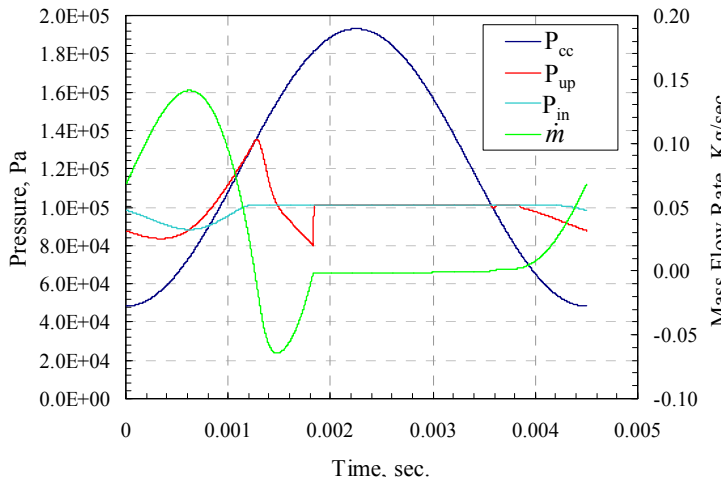

(a)

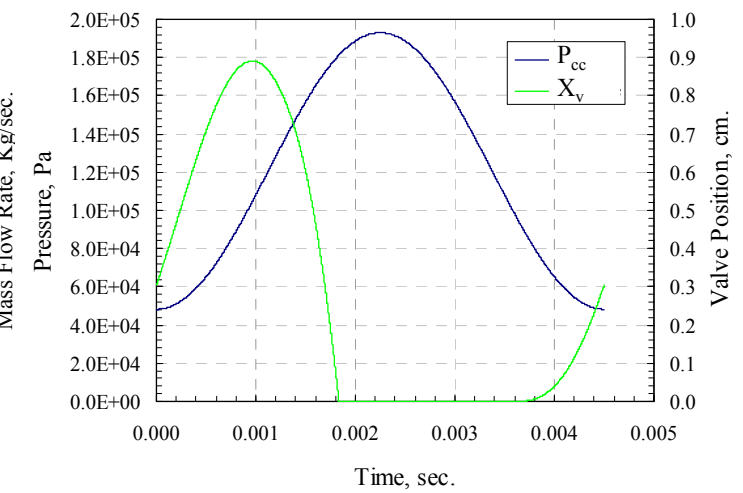

(b)

Figure 5.- Inlet and valve model limit cycle responses to a sinusoidal approximation of the pulsejet combustion chamber pressure: (a) upstream pressures and mass flow, (b) reed valve position.

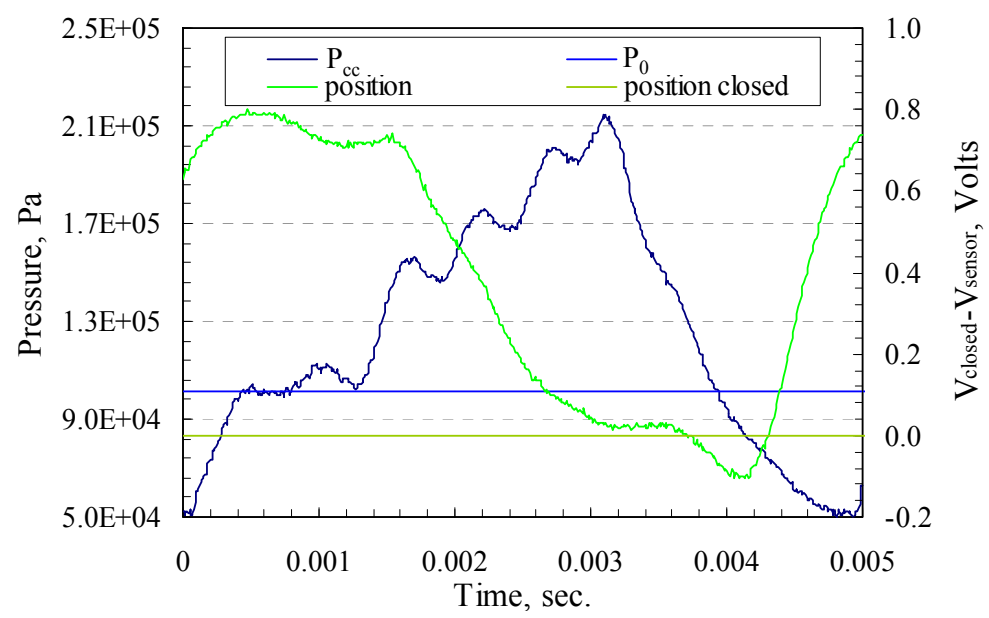

Figure 6.-Measured pulsejet combustion chamber pressure and reed valve position. 


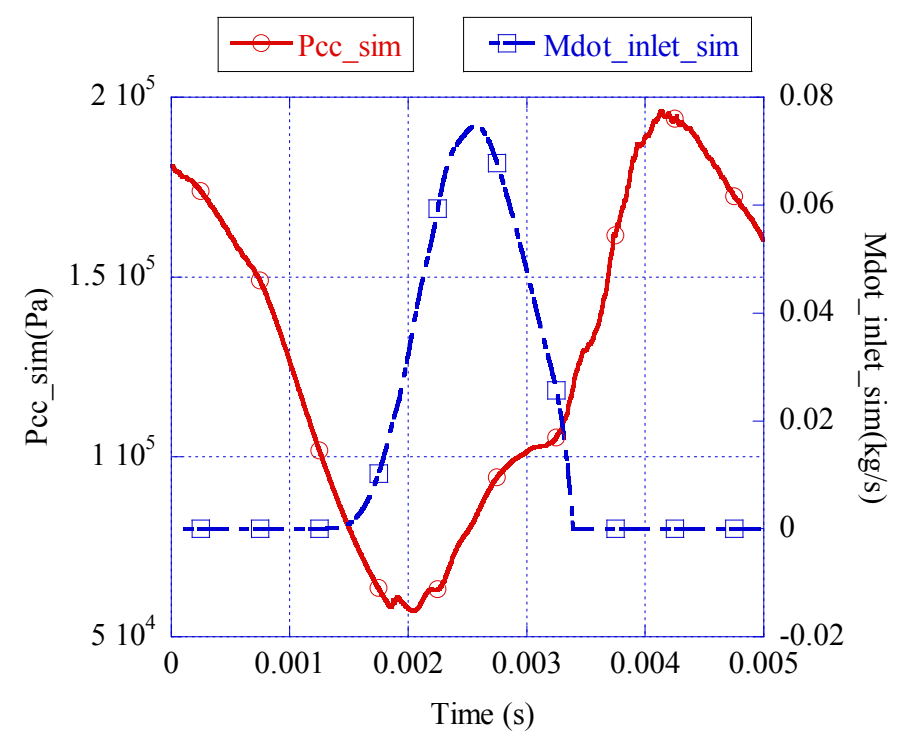

Figure 7.—Simulated pulsejet inlet mass flow rate and combustion chamber pressure.

Figure 7 presents the pulsejet simulation (with the valve head sub-model implemented) combustion chamber pressure and inlet mass flow rate over the course of one limit cycle. In the simulation model, negative flow (flow going from the combustion chamber to the valve head) is not allowed due to the numerical instability caused by the negative flow. Comparing figure 7 with figure 5(a), it is evident that the inlet sub-model is correctly implemented. The peak mass flow rate does not occur at the lowest combustion chamber pressure, but rather about $0.0005 \mathrm{~s}$ later. More importantly, the cycle-averaged inlet mass flow rate increases from $0.012 \mathrm{~kg} / \mathrm{s}$ in previous work to $0.021 \mathrm{~kg} / \mathrm{s}$. The experimentally measured mass flow rate is $0.026 \mathrm{~kg} / \mathrm{s}$ (ref. 20), providing further indication that the valve head sub-model is correct. This improvement, increasing the inlet mass flux by 75 percent, is due solely to the utilization of the inlet sub-model and is critical to accuracy of the final simulation results because with increased mass flow rate of reactants, the total thrust increases. This is a desirable effect because previously calculated thrust was smaller than the experimentally measured thrust. Additionally, the correct phase relationship between inlet mass flow rate and combustion chamber pressure is expected to improve prediction of flow dynamics in and out of the pulsejet, which will be evident when examining the exhaust flow later.

\section{Simulated and Experimental Flow Comparisons and Discussion}

As stated in the introduction, the objective of this paper is to validate simulation results by comparing them with experimental data from the pulsejet. Such comparisons are made in this section and include global quantities, such as cycle-averaged thrust and mass flow, as well as time-dependant, local quantities such as combustion chamber pressure, and exhaust field velocities.

The experimentally measured thrust is $4.3 \mathrm{lbf}$, or $19.13 \mathrm{~N}$, with a standard deviation of 1.4 percent (ref. 20). The simulated result is shown in figure 8. Thrust is calculated as the integral of the momentum force at the pulsejet exit plane, i.e.

$$
\tau=\int \dot{m}_{e} V_{e} d A_{e}
$$

For both the previous and current results, the thrust profiles for three cycles are shown in this figure; cycle-averaged thrusts are computed to be 19.46 and $16.44 \mathrm{~N}$ for current and previous results, respectively. Compared to measurements, the error is 1.7 percent for current result and 14 percent for previous result. 


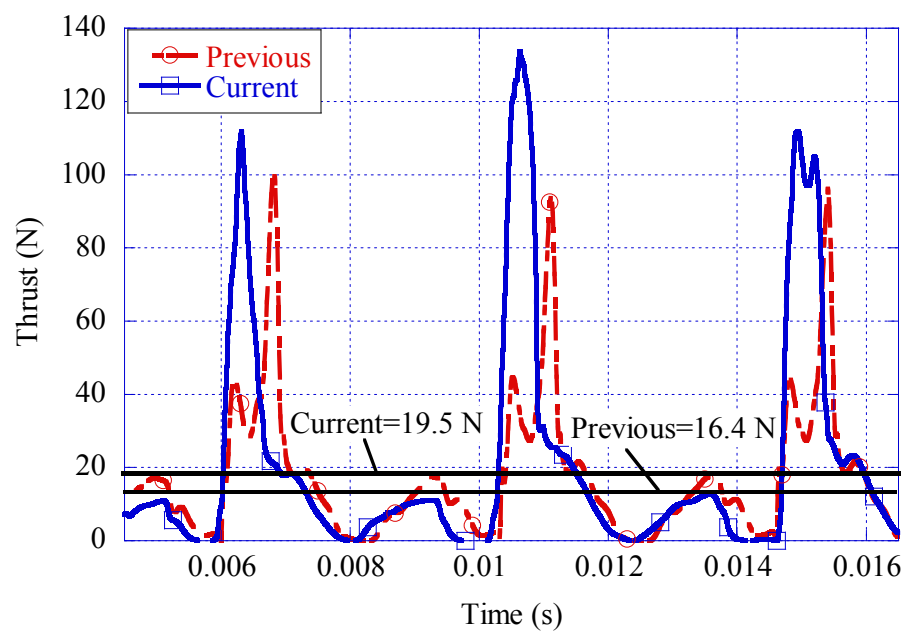

Figure 8.-Simulation results for the pulsejet thrust.

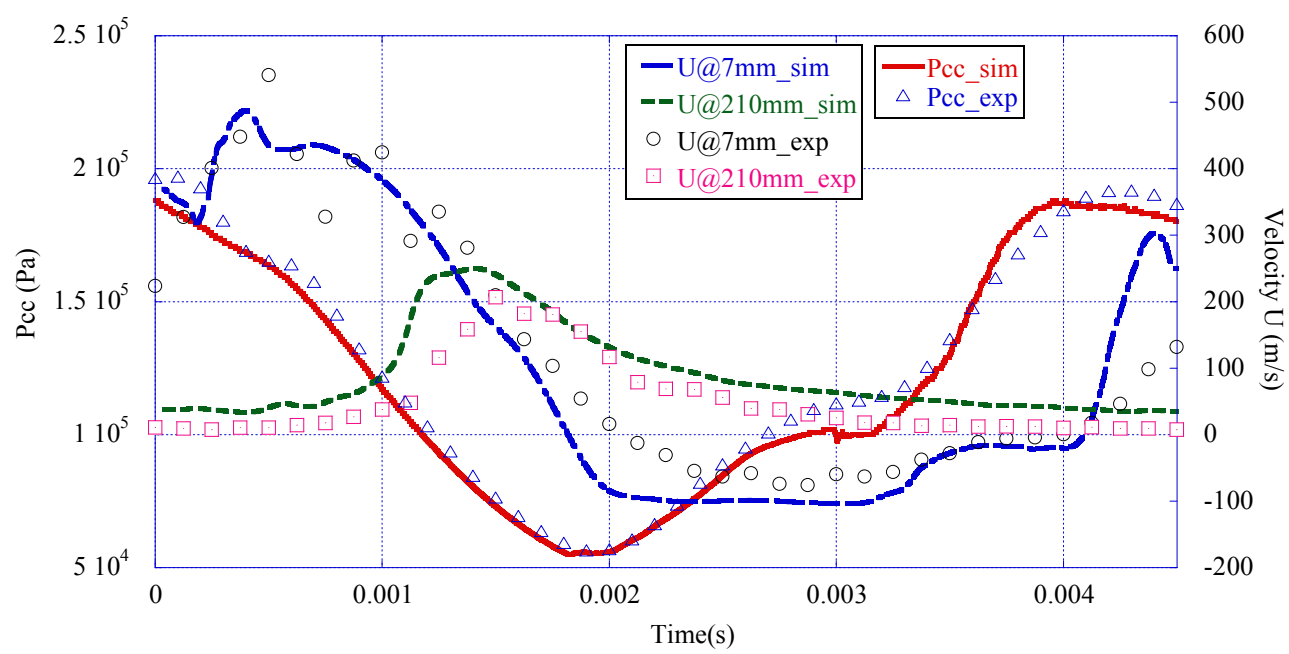

Figure 9.—Phase-locked centerline exhaust velocities.

Figure 9 shows the simulated and experimentally measured centerline exhaust velocities, at 7 and $210 \mathrm{~mm}$ downstream of the pulsejet exit plane, over the course of one cycle. The experimental data give the average value over an approximately $6 \mathrm{~mm}$ span across the centerline, while the simulation data give the exit velocity exactly at the centerline. Combustion chamber pressure is also included in the plot in order to examine the pressure-velocity phase relationship. Time zero represents the time when combustion chamber pressure reaches its peak value. In experiments, the PIV data are taken at $125 \mu$ sec. intervals commencing approximately $300 \mu \mathrm{sec}$ after time zero. This $300 \mu \mathrm{sec}$ delay is therefore applied to all the simulation results in this paper. It is evident that simulation agrees well with measurements in terms of pressure, velocity, and their phase difference. The simulated velocity at $210 \mathrm{~mm}$ downstream of the exit is higher than the measured one. This may be caused by the fact that flow velocity diffuses as it travels downstream. Thus, the average value over several points by the centerline may be smaller than the centerline velocity.

Figure 10 compares computed and measured vorticity contours at three different instants during the pulsejet cycle. In each plot, the upper half is the measured PIV data and the lower half is the simulated data. The "+" sign in the PIV data represents the location of the highest vorticity value observed in the vortex region. This value, shown on the right hand side of the PIV contour, is used to scale the color spectrum shown, thereby accentuating the vortex. It can be seen from these plots that the simulated vortex 
has the same convective speed as the one in measurements. The vorticity levels also agree well between simulation result and experimental data. Figure 10(a) shows that the starting vortex ring has just formed from the pulsejet exit shear layer and is still attached to the trailing jet. Possibly owing to this attachment, the vortex in figure 10(a) has the highest vorticity value in the vortex core. As the vortex travels downstream, it starts to detach from the trailing jet. As a result of this, and dissipative forces, the vorticity level of the vortex ring begins to decrease, as shown in figure 10(b). Later, in figure 10(c), the vortex is completely detached from the trailing jet, and the vorticity level continues to decrease.

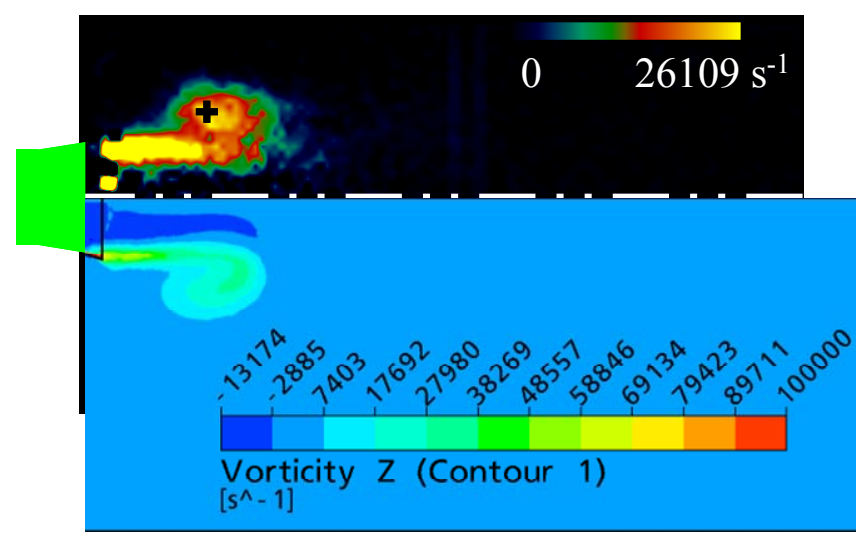

(a)

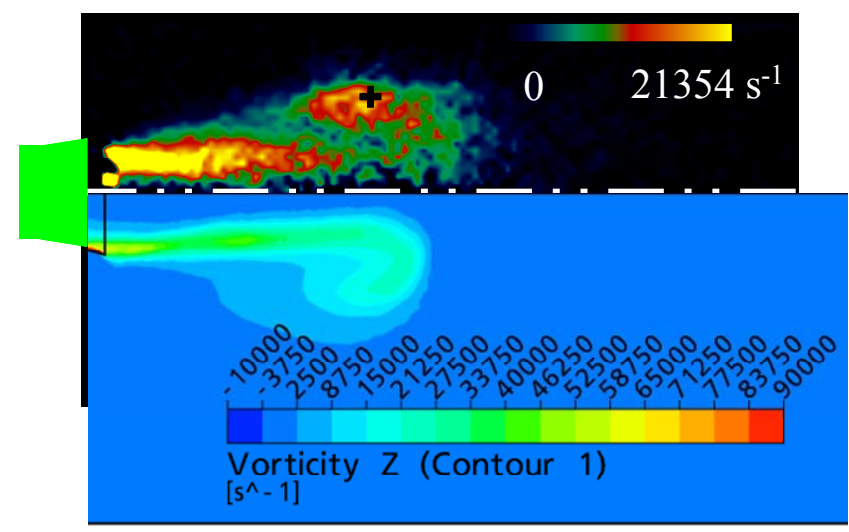

(b)

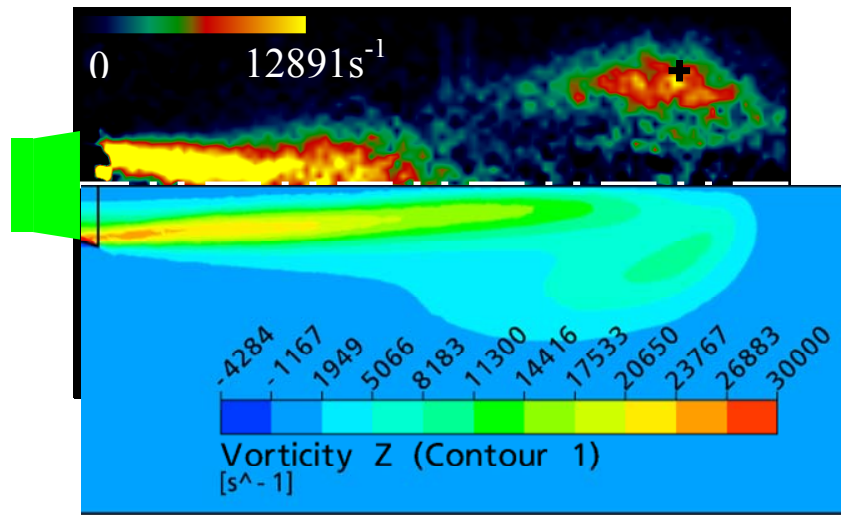

(c)

Figure 10.-Experimentally measured and simulated vorticity contours at (a) $\mathrm{T}=0.000375 \mathrm{~s}$, (b) $\mathrm{T}=0.00075 \mathrm{~s}$, and (c) $\mathrm{T}=0.0015 \mathrm{~s}$. 


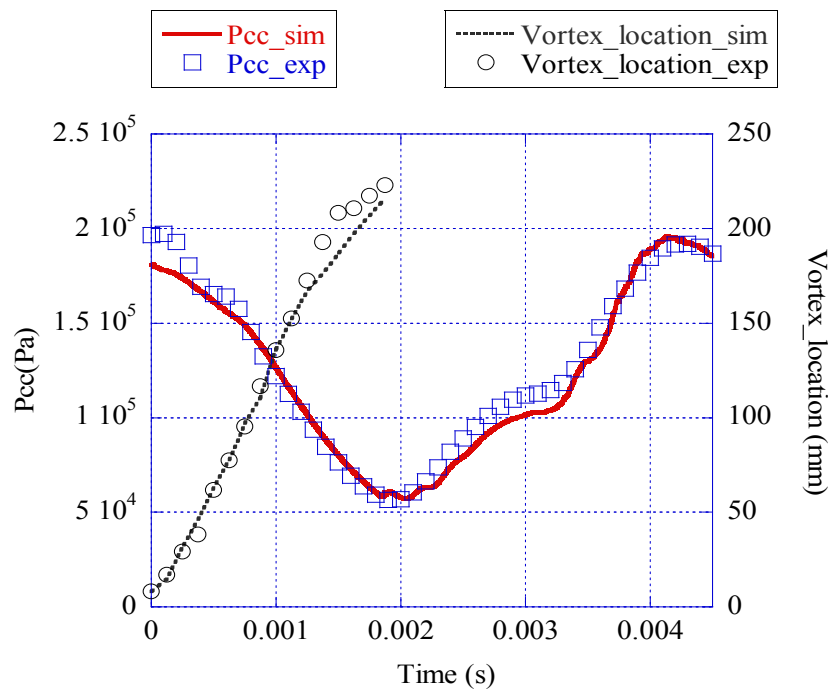

Figure 11.-Measured and simulated vortex location and combustion chamber pressure versus time.

To further verify the simulation results, computational and experimental data on vortex location and combustion chamber pressure are compared in figure 11. The location of the vortex is represented by the axial distance from the exit plane to the point in the vortex with the highest vorticity value. From time zero, the vortex locations at each $125 \mu \mathrm{sec}$. interval are compared between simulation and experiment. The comparison shows a good agreement with small but consistent differences after $0.00125 \mathrm{~s}$. One possible reason for this difference is that the vortex has traveled to the edge of the simulation domain, where a constant pressure of $1.01 \mathrm{kPa}$ was specified. This plot also reveals that for the first $0.0015 \mathrm{sec}$, although the velocity at the centerline changes from about 500 to $200 \mathrm{~m} / \mathrm{s} \mathrm{(fig.} \mathrm{9),} \mathrm{the} \mathrm{vortex} \mathrm{ring} \mathrm{travels}$ at a relatively constant speed of about $135 \mathrm{~m} / \mathrm{s}$ according to the data.

\section{Conclusion}

This paper provides direct comparisons between experimental measurements and simulation results of mechanically valved pulsejet. The simulation contains a new inlet sub-model which simulates the valve head dynamics and is integrated into the code. As a result, this new model is able to correctly predict the total thrust and time-averaged mass flow rate, an improvement over the previous model.

Besides thrust, the simulation model is fully validated by comparisons with experimental data on combustion chamber pressure, exit flow velocity, pressure-velocity phase relationship, vortex ring location and vorticity level. The results obtained indicate that the peak inlet mass flow rate occurs about 1/9th of a cycle after the minimum in combustion chamber pressure. The inertia effect of the flow inside the valve head plays a key role in the inlet mass flow rate modeling. Without inertia, the model tends to underpredict the inlet mass flow rate, by as much as 75 percent.

The comparison of the simulated pulsejet exit flowfield with that measured experimentally also verifies simulation results. It may well be possible therefore, to utilize the developed simulation to gain insights into the role of the emitted vortex in achieving substantial thrust augmentation and mixing, when an ejector is present behind the pulsejet. 


\section{References}

1. Moore, M., "Personal Air Vehicles: A Rural/Regional and Intra-Urban On-Demand Transportation System," AIAA Paper 2003-2646, July 2003.

2. Skorupa, J., "Military Airlift — Catching the Next Wave," AIAA paper 2003-2747, July 2003.

3. Paxson, D.E., "Ejector Enhanced Pulsejet Based Pressure Gain Combustors: An Old Idea With a New Twist," AIAA Paper 2005-4216, July, 2005.

4. Kentfield, J.A.C., Nonsteady, One-Dimensional, Internal, Compressible Flows, Oxford University Press, 1993, pp. 191-235.

5. Putnam, A.A., Belles, F.E., and Kentfield, J.A.C., "Pulse Combustion," Progress in Energy and Combustion Science, vol. 12, 1986, pp. 43-79.

6. T. Maxworthy, "Turbulent Vortex Ring," J. Fluid Mech. 64, 227 (1974).

7. M. Gharib, E. Rambod, and K. Shariff, "A Universal Time Scale for Vortex Ring Formation," J. Fluid Mech. 360, 121 (1998).

8. J.H. Arakeri, D. Das, A. Krothapalli, and L. Lourenco, "Vortex Ring Formation at the Open end of a Shock Tube: A Particle Image Velocimetry Study," Phys. Fluids 16, 1008 (2004).

9. M. Rosenfeld, E. Rambod, and M. Gharib, "Circulation and Formation Number of Laminar Vortex Rings," J. Fluid Mech. 376, 297 (1998).

10. S. James and C.K. Madnia, "Direct Numerical Simulation of a Laminar Vortex Ring," Phys. Fluids 8, 2400 (1996).

11. M. Nitsche, "Scaling Properties of Vortex Ring Formation at a Circular Tube Opening," Phys. Fluids 8, 1848 (1996).

12. Wilson, J., Wernet, M.P., Paxson, D.E., "Vortex Rings Generated by a Shrouded Hartmann-Sprenger Tube," AIAA Journal, vol. 44, no. 11, 2006, pp. 2706-2719.

13. Paxson, D.E., Wernet, M.P., John, W.T., "Experimental Investigation of Unsteady Thrust Augmentation Using a Speaker-Driven Jet," AIAA Journal, vol. 45, no. 3, 2007, pp. 607-615.

14. Erickson, R. and Zinn, B., "Numerical Investigation of the Effect of Energy Addition Processes on Pulsejet Performance," AIAA Paper 2004-1210, Jan. 2004.

15. Litke P., Schauer, F., and Paxson, D.E., "Assessment of the Performance of a Pulsejet and Comparison with a Pulsed-Detonation Engine," AIAA Paper 2005-228, Jan. 2005.

16. Kentfield, J.A.C., Rehman, A., and Cronje J., "Performance of Pressure-Gain Combustors Without Moving Parts," Journal of Energy, vol. 4, no. 2, 1980, pp. 56-63.

17. T. Geng, A. Kiker, Jr., R. Ordon, A.V. Kuznetsov, T.F. Zeng, and W.L. Roberts, "Combined Numerical and Experimental Investigation of a Hobby-Scale Pulsejet," AIAA J. of Propulsion and Power, vol. 23, no. 1, pp. 186-193, 2007.

18. T. Geng, M.A. Schoen, A.V. Kuznetsov, and W.L. Roberts, "Combined Numerical and Experimental Investigation of a 15-Centimeter Valveless Pulsejet," J. of Flow, Turbulence and Combustion, vol. 78, pp. 17-33, 2007.

19. T. Geng, F. Zheng, A.P. Kiker, A.V. Kuznetsov, and W.L. Roberts, "Experimental and Numerical Investigation of an 8-Centimeter Valveless Pulsejet," J. of Experimental Thermal and Fluid Science, vol. 31, pp. 641-647, 2007.

20. Paxson, D.E., Wilson, J., and Dougherty, K., "Unsteady Ejector Performance: An Experimental Investigation Using a Pulsejet Driver," AIAA Paper 2002-3915, July 2002.

21. Paxson, D.E., Litke, P.J., Schauer, F.R., Bradley R.P., Hoke, J.L., "Performance Assessment of a Large Scale Pulsejet-Driven Ejector System," AIAA Paper 2006-1021, Jan. 2006.

22. Bardina, J.E., Huang, P.G., and Coakley, T.J., "Turbulence Modeling Validation Testing and Development," NASA Technical Memorandum 110446, 1997. 



\section{Appendix-Optical Sensor Detail}

The optical position sensor constructed for this work is shown installed in the composite photograph of figure 12. An infrared LED transmits light down one of the fiber-optic rods shown. This light is emitted from the end of the rod, which is placed in close proximity to the face of the reed valve, in the closed position. The emitted light is therefore reflected from the valve face, and some of it is transmitted through the second fiber optic rod, which terminates into an infrared phototransistor. The light is sufficient to allow the transistor to pass current which, passing also through a resistor, registers a high voltage signal. When the reed valve opens, less of the reflected LED light reaches the transistor, causing the signal voltage to drop.

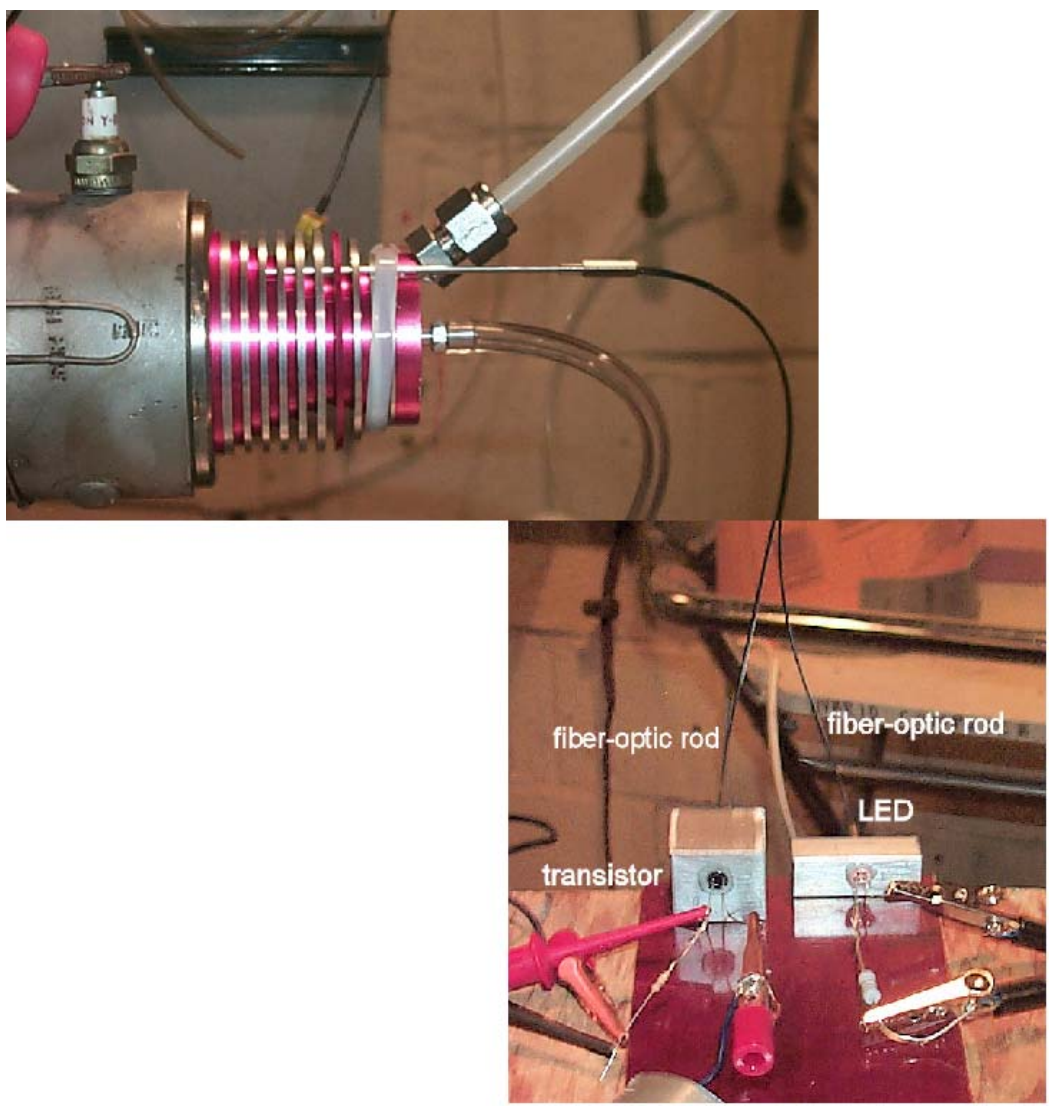

Figure 12.-Optical reed valve position sensor. 


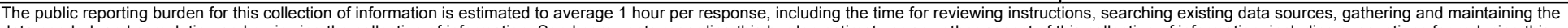

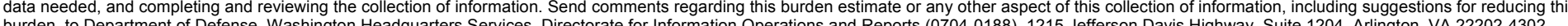

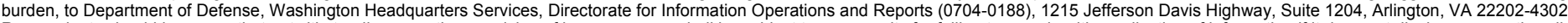

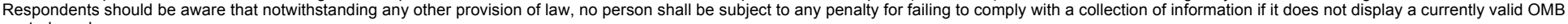
control number.

PLEASE DO NOT RETURN YOUR FORM TO THE ABOVE ADDRESS
1. REPORT DATE (DD-MM-YYYY)
2. REPORT TYPE
3. DATES COVERED (From - To)
01-10-2008
Technical Memorandum

\section{TITLE AND SUBTITLE}

Comparison Between Numerically Simulated and Experimentally Measured Flowfield

Quantities Behind a Pulsejet

5a. CONTRACT NUMBER

5b. GRANT NUMBER

5c. PROGRAM ELEMENT NUMBER

5d. PROJECT NUMBER

AUTHOR(S)

Geng, Tao; Paxson, Daniel, E.; Zheng, Fei; Kuznetsov, Andrey, V.; Roberts, William, L. 5e. TASK NUMBER

5f. WORK UNIT NUMBER

WBS 561581.02.08.03.17.02

8. PERFORMING ORGANIZATION

REPORT NUMBER

E-16597

National Aeronautics and Space Administration

John H. Glenn Research Center at Lewis Field

Cleveland, Ohio 44135-3191

9. SPONSORING/MONITORING AGENCY NAME(S) AND ADDRESS(ES)

National Aeronautics and Space Administration

Washington, DC 20546-0001

\section{SPONSORINGIMONITORS ACRONYM(S) \\ NASA; AIAA}

\section{SPONSORING/MONITORING REPORT NUMBER \\ NASA/TM-2008-215432; AIAA-2008- 5046}

\section{DISTRIBUTION/AVAILABILITY STATEMENT}

Unclassified-Unlimited

Subject Category: 07

Available electronically at http://gltrs.grc.nasa.gov

This publication is available from the NASA Center for AeroSpace Information, 301-621-0390

\section{SUPPLEMENTARY NOTES}

\section{ABSTRACT}

Pulsed combustion is receiving renewed interest as a potential route to higher performance in air breathing propulsion systems. Pulsejets offer a simple experimental device with which to study unsteady combustion phenomena and validate simulations. Previous computational fluid dynamic (CFD) simulation work focused primarily on the pulsejet combustion and exhaust processes. This paper describes a new inlet sub-model which simulates the fluidic and mechanical operation of a valved pulsejet head. The governing equations for this sub-model are described. Sub-model validation is provided through comparisons of simulated and experimentally measured reed valve motion, and time averaged inlet mass flow rate. The updated pulsejet simulation, with the inlet sub-model implemented, is validated through comparison with experimentally measured combustion chamber pressure, inlet mass flow rate, operational frequency, and thrust. Additionally, the simulated pulsejet exhaust flowfield, which is dominated by a starting vortex ring, is compared with particle imaging velocimetry (PIV) measurements on the bases of velocity, vorticity, and vortex location. The results show good agreement between simulated and experimental data. The inlet sub-model is shown to be critical for the successful modeling of pulsejet operation. This sub-model correctly predicts both the inlet mass flow rate and its phase relationship with the combustion chamber pressure. As a result, the predicted pulsejet thrust agrees very well with experimental data.

\section{SUBJECT TERMS}

Combustor; Gas turbine engine; Pulsejet engines

\begin{tabular}{|c|c|c|c|c|}
\hline 16. SECURI & ASSIFICATION & & 17. LIMITATION OF & 18. NUMBER \\
\hline $\begin{array}{l}\text { a. REPORT } \\
U\end{array}$ & $\begin{array}{l}\text { b. ABSTRACT } \\
U\end{array}$ & $\begin{array}{l}\text { c. THIS } \\
\text { PAGE } \\
\text { U }\end{array}$ & UU & $\begin{array}{c}\text { PAGES } \\
18\end{array}$ \\
\hline
\end{tabular}

19a. NAME OF RESPONSIBLE PERSON STI Help Desk (email:help@sti.nasa.gov) 19b. TELEPHONE NUMBER (include area code) 301-621-0390 

